\title{
Rotational stability and clinical outcomes of a new one piece toric intraocular lens with anchor-wing haptics
}

lichiro Sugita ${ }^{*}$, Tomoichiro Ogawa ${ }^{2,3}$, Kazuo Ichikawa ${ }^{4}$, Takahide Okita ${ }^{1}$, Kazuno Negishi $^{5}$, Tadashi Nakano ${ }^{2}$ and Hiroshi Tsuneoka ${ }^{2}$

\begin{abstract}
Background: To evaluate the safety and efficacy of a new toric intraocular lens (IOL) with anchor-wing haptics.

Methods: The new toric IOL with anchor-wing haptics (NS60YT, NIDEK Co., Ltd.) was implanted in eligible patients with age-related cataracts with preoperative corneal astigmatism of $1.0 \mathrm{D}$ or greater at a university hospital and two private hospitals in Japan. The following IOL cylinder powers were evaluated: 1.50 D (NS60YT3), 2.25 D (NS60YT4), 3.00 D (NS60YT5) and $4.50 \mathrm{D}$ (NS60YT7). All patients were assessed out to 12 months postoperatively. The primary endpoint was visual acuity (VA) with spherical addition at 6 months postoperatively, and the primary analysis calculated the proportion of eyes with VA with spherical addition of 0.1 logMAR or better. The magnitude of rotation was compared to the intended axis of $\mathrm{IOL}$ implantation at each postoperative examination. Adverse events were evaluated for the safety analysis.
\end{abstract}

Results: This study enrolled 64 eyes of 53 patients. At 6 months postoperatively, for all IOL powers, VA with spherical addition of 0.1 logMAR or better was achieved in 90\% [95\% confidence interval (CI): 80-96] of eyes. The mean $\mathrm{IOL}$ rotation was $5.3 \pm 4.3^{\circ}$ at 12 months postoperatively. The mean magnitude of rotation ranged from $1.9^{\circ}$ to $2.5^{\circ}$ between each postoperative examination from 1 day to 12 months. There were no vision-threatening intraoperative or postoperative complications for the duration of the study.

Conclusions: The NS60YT IOL remained stable after implantation and was efficacious for treating $1.00 \mathrm{D}$ or greater astigmatism in patients with senile cataracts.

Trial registration: This study was registered at ClinicalTrials.gov (NCT03242486) on August 8, 2017 - Retrospectively registered.

Keywords: Toric intraocular lens, Intraocular lens, Corneal astigmatism, Cataract, Cataract surgery, Rotational stability, Anchor-wing haptics

*Correspondence: iichiro@sugita.or.jp

1 Sugita Eye Hospital, 5-1-30, Sakae, Naka-ku, Nagoya-shi, Aichi 460-0008, Japan

Full list of author information is available at the end of the article

\begin{abstract}
Background
The reduction of astigmatism during cataract surgery is an important factor in visual function and postoperative patient satisfaction. Approximately $35 \%$ of patients with cataract have preoperative corneal astigmatism of $1.0 \mathrm{D}$ or greater and approximately $20 \%$ have $1.5 \mathrm{D}$ or greater astigmatism [1-4]. Residual astigmatism after phacoemulsification and intraocular lens (IOL) implantation is a
\end{abstract} original author(s) and the source, provide a link to the Creative Commons licence, and indicate if changes were made. The images or other third party material in this article are included in the article's Creative Commons licence, unless indicated otherwise in a credit line to the material. If material is not included in the article's Creative Commons licence and your intended use is not permitted by statutory regulation or exceeds the permitted use, you will need to obtain permission directly from the copyright holder. To view a copy of this licence, visit http://creativecommons.org/licenses/by/4.0/. The Creative Commons Public Domain Dedication waiver (http://creativeco mmons.org/publicdomain/zero/1.0/) applies to the data made available in this article, unless otherwise stated in a credit line to the data. 
significant cause of suboptimal vision, increased spectacle dependence or patient dissatisfaction $[5,6]$. There are a variety of methods currently used for treating cataracts with co-existing corneal astigmatism, including but not limited to, implantation of supplementary sulcus-fixated IOLs, implantation of pinhole IOLs, laser refractive surgery for a corneal "touch-up", or toric IOL. The advantages of toric IOL implantation include a wider range of correction and the use of one procedure to simultaneously correct the refractive error, reducing the burden on the patient and the surgeon [7]. The Aktis toric (Model NS60YT; Nidek Co., Ltd.) is a newly developed IOL that is based on the existing monofocal Nex-Acri ${ }^{\circledR}$ AA 1P IOL platform (Nidek Co., Ltd.). Rotational stability for this IOL is maintained by anchor-wing haptics. In this prospective, multicenter study, we present the stability and clinical outcomes of NS60YT implantation for the correction of moderate to high astigmatism.

\section{Methods}

This single-arm, open-label, multicenter, prospective clinical study evaluated implantation of the NS60YT in patients with age-related cataracts at a university hospital and two private hospitals in Japan. This study was approved by the Jikei University Hospital Institutional Review Board for Medical Devices, the Sugita Eye Hospital Institutional Review Board, and the Joint Institutional Review Board of the hospitals. The study adhered to the Declaration of Helsinki and the Japanese Ministerial Ordinance on Good Clinical Practice for Medical Devices (GCP). This manuscript adheres to the CONSORT guidelines. The study protocol is available at https://clinicaltrials.gov. Written informed consent was obtained from all patients before participation. The study period was from December 2014 to November 2017. The duration of follow up was 12 months postoperatively.

\section{Intraocular lens}

The NS60YT is a single-piece toric IOL based on the Nex-Acri ${ }^{\circledR}$ series (Nidek Co., Ltd.) (Fig. 1). The optical diameter is $6.0 \mathrm{~mm}$ and the overall diameter is $13.0 \mathrm{~mm}$ including the anchor-wing haptics. The lens is a biconvex lens and the rear surface is aspheric $(-0.15 \mu \mathrm{m})$. The cylindrical power is placed on the front of the lens for the correction of corneal astigmatism. The IOL consists of hydrophobic soft acrylic resin with an ultraviolet absorber and proprietary material to enhance compatibility with the injector. The lens has two dots on either side of the optic periphery, indicating the flattest meridian for marking the cylinder axis. This study evaluated 4 different toric IOL powers as follows: $1.50 \mathrm{D}, 2.25 \mathrm{D}, 3.00$ $\mathrm{D}$ and $4.50 \mathrm{D}$ (Table 1).

\section{Patients}

Patients were included if they were over 40 years old with age-related cataracts in one or both eyes with a pupil diameter of $5.0 \mathrm{~mm}$ or larger at mydriasis and had 1.0 $\mathrm{D}$ or greater preoperative corneal astigmatism. Other inclusion criteria were, a predicted postoperative astigmatism less than $0.5 \mathrm{D}$, and the predicted postoperative visual acuity (VA) with spherical addition of $0.1 \log$ MAR or better. "VA with spherical addition" is visual acuity measured under conditions where a spherical trial lens is added to correct the postoperative spherical refractive error determined before surgery for each patient.

Patients were excluded if they had irregular corneal astigmatism, axial length $>28 \mathrm{~mm}$, and other diseases or complications that might affect the efficacy and safety of IOL implantation.

\section{Preoperative examination}

Within 60 days prior to surgery, the patient underwent thorough ophthalmic examinations including, slit lamp microscopy, corneal topography (OPD-Scan ${ }^{\circledR}$ III; Nidek Co., Ltd.) for measurement of corneal astigmatism, measurement of pupil diameter, tonometry, fundus examination, and axial length measurement (IOLMaster ${ }^{\circledR}$; Carl Zeiss Meditec AG).

\section{Calculation of intraocular lens power using a toric calculator}

The IOL spherical power was selected by the surgeon based on the desired postoperative refractive error for each patient using the biometry values. The SRK/T formula was used for all eyes. The A-constants (119.7) were adjusted for each clinical site based on the constant for the Nex-Acri ${ }^{\circledR}$ AA 1P that is the same shape as NS60YT. The Nidek Toric Calculator For Clinical Trials was used to select cylinder power and to calculate the angle of implantation. Data entry of the preoperative corneal astigmatism, the surgically induced astigmatism for each surgeon, and the location of the incision allows calculation of the predicted postoperative corneal astigmatism, the IOL implantation axis, and the predicted postoperative residual astigmatism for each model. Based on these variables, the surgeons selected the optimum IOL model that predicted the lowest postoperative astigmatism.

\section{Surgery}

Once the axis of implantation was verified with topographic data just prior to surgery, the patient was seated at a slit lamp and the surgeon used a gentian violet pen to mark the 3-o'clock, 6-o'clock and 9-o'clock positions. Intraoperatively, once the patient is supine and just prior to IOL implantation, the absence of head tilt is verified, and the gentian violet marks are used with a protracting 


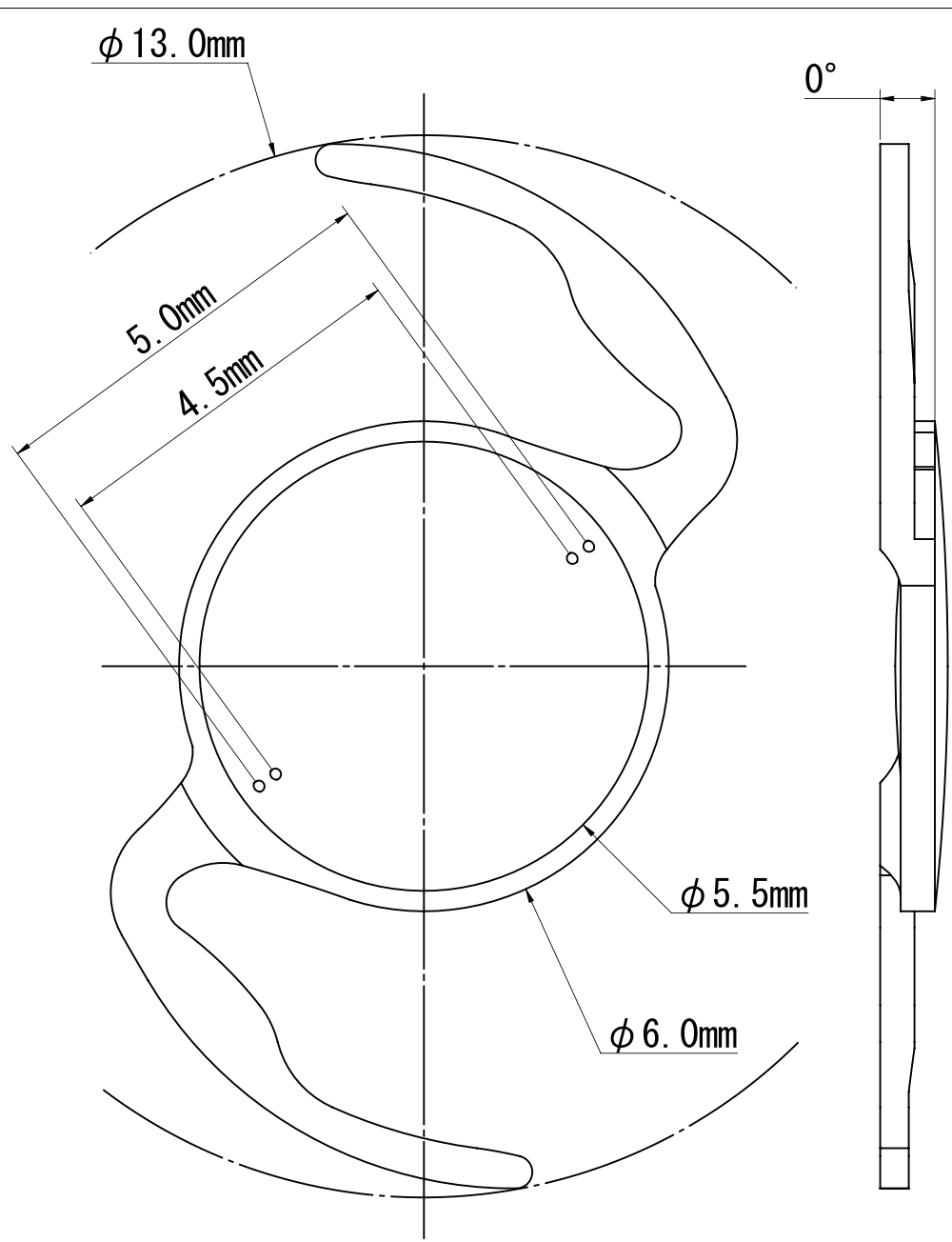

Fig. 1 Design specifications of the NS60YT intraocular lens

device to find the target meridian. The target meridian was marked on the corneo-scleral junction. A paracentesis was created and a dispersive viscoelastic was delivered to the anterior chamber to protect the corneal endothelium. A 2.2 to $2.5 \mathrm{~mm}$ corneal, scleral or corneoscleral incision was created. A well-centered manual capsulorhexsis was created and the cataractous lens

Table 1 Cylindrical power of each model of the NS60YT intraocular lens

\begin{tabular}{lll}
\hline Model name & IOL surface power (D) & $\begin{array}{l}\text { Power at the } \\
\text { Corneal Plane } \\
\text { (D) }\end{array}$ \\
\hline NS60YT3 & 1.50 & 1.05 \\
NS60YT4 & 2.25 & 1.57 \\
NS60YT5 & 3.00 & 2.08 \\
NS60YT7 & 4.50 & 3.11 \\
\hline
\end{tabular}

was removed by phacoemulsification and aspiration. A cohesive viscoelastic was delivered followed by delivery of the IOL into the capsular bag using an injector (NexIJ; Nidek Co., Ltd.). The IOL was unfolded and rotated close to the target meridian and the viscoelastic was removed. The IOL was rotated to ensure the toric axis marks aligned with the target meridian and the lens was centered. Although an automated system for IOL alignment would have be ideal, the study protocol was written in 2013 and we did not have equipment or resources to acquire automated intraoperative images at that time. In patients scheduled for bilateral surgery, the fellow eye underwent surgery after the initial eye was evaluated at 1 week postoperatively and there were no complications.

\section{Postoperative examination}

Postoperative examinations were performed the day after surgery (1-2 days), 1 week after surgery (7-14 days), 
1 month after surgery (30-60 days), 3 months after surgery (90-150 days), 6 months after surgery (180240 days), and 12 months after surgery (360-420 days). Postoperative examinations included slit lamp microscopy, tonometry, fundus examination, measurements of corneal curvature with corneal topography, UCVA, VA with spherical addition (VA corrected with "intended postoperative spherical refractive error"), sphere-corrected visual acuity (VA corrected with "actual postoperative spherical refractive error"), best corrected distance visual acuity (BCVA), IOL axis evaluation, and a patient questionnaire (only at 6 months postoperatively). Spherecorrected VA is the visual acuity when only the sphere was corrected from the VA with spherical addition based on the postoperative spherical error.

The IOL axis was measured manually using slit lamp photography or from images obtained with anterior segment imaging devices (KATS-1000; Konan medical Co., Ltd. and Casia; Tomey Corp.). The patient was seated at the slit lamp and the correct head position (no tilt) was verified prior to acquiring photographs. Deviation between the corneal astigmatic axis and the axis marks on the IOL was determined by using a protractor. The image was regarded as horizontal, and the angle was measured between the horizontal line and the toric mark. The patient questionnaire classified current vision into five rankings as follows: "very satisfied", "satisfied", "neither satisfied nor dissatisfied", "dissatisfied", and "very dissatisfied".

Data were collected on all postoperative adverse events irrespective of causality. The following adverse events that may occur after cataract surgery were summarized as anticipated adverse events at every postoperative examination: secondary cataract (requiring posterior capsulotomy), macular degeneration, macular edema, hypopyon, infectious and noninfectious endophthalmitis, pupil block, retinal detachment, corneal edema, iritis, increased intraocular pressure (IOP), and IOL dislocation. Increased IOP was defined as $23 \mathrm{mmHg}$ or higher and an increase of $5 \mathrm{mmHg}$ or higher compared to the preoperative IOP.

\section{Statistical analysis}

We used previous studies of toric IOLs that targetted emmetropia as the historical control to determine the number of cases that achieved a postoperative UCVA of $0.1 \operatorname{logMAR}$ or better [8-10]. The analysis indicated 47 eyes were required for NS60YT3, NS60YT4, NS60YT5 (significance level $\alpha=0.05$, power $1-\beta=0.80$ ), based on the threshold response rate $(\pi 0) 0.5$ and the expected response rate $(\pi 1)$ 0.7. For high astigmatism (NS60YT7), data were collected on only 5 eyes due to the lack of appropriate patients.
The primary endpoint was the VA with spherical addition 6 months after surgery, and the primary analysis calculated the proportion of VA with spherical addition of $0.1 \log$ MAR or better and a $95 \%$ confidence interval (CI). The Clopper-Pearson method was used to calculate $95 \%$ CIs. Secondary endpoints included UCVA, sphere-corrected VA, BCVA, refractive cylinder correction, and the magnitude of IOL rotation. Visual acuity was recorded in decimal notation at all sites, however for statistical analysis and consistency, all values were reported in logMAR. The magnitude of IOL rotation was calculated as the absolute value of the difference between the actual IOL axis and preoperative IOL insertion axis calculated with the Nidek Toric Calculator For Clinical Trials.

Safety endpoints included the presence, absence, and incidence of adverse events after IOL insertion, and the presence or absence of anticipated adverse events. SAS (Version 9.3, SAS Institute Inc.) was used for statistical analysis. $P<0.05$ was considered statistically significant.

\section{Results}

The study sample was comprised of 64 eyes of 53 patients. Two eyes of one patient were excluded from all analyses due to non-compliance with GCP because the consent forms were misplaced. One patient died after 6 months examination due to reasons unrelated to cataract surgery. Therefore, the full analysis set for efficacy, included 62 eyes of 52 patients at 6 months postoperatively and 61 eyes of 51 patients at 12 months postoperatively. Table 2 presents patient demographics, baseline examination data and IOL calculation data. The mean age at enrollment was $68.6 \pm 9.5$ years (Table 2). The mean targeted postoperative refraction was $-1.1 \pm 1.2 \mathrm{D}$ (Table 2).

\section{Primary endpoint - visual acuity with spherical addition}

Table 3 presents the postoperative VA with spherical addition of $0.1 \log$ MAR or better and the $95 \%$ CI. At 6 months, the primary endpoint was achieved in $90 \%$ (56/62 eyes) for all models, $100 \%$ (21/21 eyes), $80 \%$ (16/20 eyes), 93\% (14/15 eyes), and 83\% (5/6 eyes) for NS60YT3, NS60YT4, NS60YT5 and NS60YT7, respectively. At 12 months, $87 \%$ achieved the primary endpoint for all models.

\section{Other efficacy parameters and safety parameters Visual acuity}

Table 4 presents the UCVA, VA with spherical addition, sphere-corrected VA, BCVA and subjective cylindrical power up to 12 months postoperatively. VA with spherical addition, sphere-corrected VA and BCVA remained stable until 12 months postoperatively after 1 month postoperatively (Table 4). At 12 months postoperatively, 
Table 2 Demographics and preoperative data of patients scheduled to undergo cataract surgery with implantation of the NS60YT intraocular lens

\begin{tabular}{|c|c|c|c|c|c|}
\hline Parameter & All models & NS60YT3 & NS60YT4 & NS60YT5 & NS60YT7 \\
\hline Number of eyes, $n$ & 62 & 21 & 20 & 15 & 6 \\
\hline Number of patients, $\mathrm{n}$ & 52 & 20 & 20 & 13 & 6 \\
\hline \multicolumn{6}{|l|}{ Age } \\
\hline Mean (years) $\pm S D$ & $68.6 \pm 9.5$ & $69.1 \pm 9.2$ & $68.1 \pm 10.2$ & $66.7 \pm 10.7$ & $73.2 \pm 4.6$ \\
\hline Minimum value, maximum value & 42,84 & 54,84 & 48,84 & 42,79 & 66,79 \\
\hline \multicolumn{6}{|l|}{ Sex, $n$} \\
\hline Male & 27 & 8 & 8 & 9 & 2 \\
\hline Female & 35 & 13 & 12 & 6 & 4 \\
\hline Mean pupil diameter $(\mathrm{mm}) \pm \mathrm{SD}$ & $7.43 \pm 0.82$ & $7.57 \pm 0.62$ & $7.25 \pm 0.71$ & $7.32 \pm 0.99$ & $7.75 \pm 1.25$ \\
\hline Mean $\mathrm{AL}(\mathrm{mm}) \pm \mathrm{SD}$ & $24.21 \pm 1.33$ & $24.01 \pm 1.35$ & $23.99 \pm 1.47$ & $24.77 \pm 1.21$ & $24.24 \pm 0.92$ \\
\hline Mean preoperative corneal astigmatism (D) $\pm S D$ & $1.73 \pm 0.54$ & $1.32 \pm 0.18$ & $1.63 \pm 0.24$ & $1.95 \pm 0.30$ & $2.99 \pm 0.47$ \\
\hline \multicolumn{6}{|l|}{ Preoperative corneal astigmatic axis, $n$ (\%) } \\
\hline WTR astigmatism $\left(0^{\circ}\right.$ to $29^{\circ}, 150^{\circ}$ to $\left.180^{\circ}\right)$ & $29(47)$ & $7(33)$ & $9(45)$ & $10(67)$ & $3(50)$ \\
\hline OBL astigmatism $\left(30^{\circ}\right.$ to $59^{\circ}, 120^{\circ}$ to $\left.149^{\circ}\right)$ & $1(2)$ & $0(0)$ & $1(5)$ & $0(0)$ & $0(0)$ \\
\hline ATR astigmatism $\left(60^{\circ}\right.$ to $\left.119^{\circ}\right)$ & $32(52)$ & $14(67)$ & $10(50)$ & $5(33)$ & $3(50)$ \\
\hline Mean postoperative target spherical refraction(D) $\pm S D$ & $-1.1 \pm 1.2$ & $-0.8 \pm 1.3$ & $-0.9 \pm 1.0$ & $-1.6 \pm 1.4$ & $-1.3 \pm 1.3$ \\
\hline
\end{tabular}

ATR Against-the-rule, AL Axial length, IOL Intraocular lens, OBL Oblique, SD Standard deviation, WTR With-the-rule

Table 3 Visual acuity with spherical addition of 0.1 logMAR or better, 6 and 12 months after cataract surgery with implantation of the NS60YT intraocular lens

\begin{tabular}{|c|c|c|c|c|c|c|}
\hline Postoperative & & All models & NS60YT3 & NS60YT4 & NS60YT5 & NS60YT7 \\
\hline \multirow[t]{3}{*}{6 months } & Number of eyes, $n$ & 62 & 21 & 20 & 15 & 6 \\
\hline & $\begin{array}{l}\text { VA with spherical addition } \\
\text { of } 0.1 \text { logMAR or better, } \\
\mathrm{n}(\%)\end{array}$ & $56(90)$ & $21(100)$ & $16(80)$ & $14(93)$ & $5(83)$ \\
\hline & $95 \%$ Cl (\%) & 80,96 & 84,100 & 56,94 & 68,100 & 36,100 \\
\hline \multirow[t]{3}{*}{12 months } & Number of eyes, n & 61 & 21 & 20 & 14 & 6 \\
\hline & $\begin{array}{l}\text { VA with spherical addition } \\
\text { of } 0.1 \text { logMAR or better, } \\
\mathrm{n}(\%)\end{array}$ & $53(87)$ & $18(86)$ & $18(90)$ & $12(86)$ & $5(83)$ \\
\hline & $95 \%$ Cl (\%) & 76,94 & 64,97 & 68,99 & 57,98 & 36,100 \\
\hline
\end{tabular}

CI Confidence interval, UCVA Uncorrected visual acuity

Table 4 Mean efficacy parameters for eyes that underwent cataract surgery with NS60YT intraocular lens implantation

\begin{tabular}{lllllcc}
\hline & 1 day & 1 week & 1 month & 3 months & 6 months & 12 months \\
\hline UCVA (logMAR) & $0.29 \pm 0.38$ & $0.28 \pm 0.40$ & $0.27 \pm 0.42$ & $0.28 \pm 0.43$ & $0.29 \pm 0.45$ & $0.28 \pm 0.42$ \\
VA with spherical addition (logMAR) & $0.08 \pm 0.19$ & $0.04 \pm 0.17$ & $0.03 \pm 0.19$ & $0.03 \pm 0.16$ & $0.02 \pm 0.17$ & $0.00 \pm 0.11$ \\
Sphere-corrected VA (logMAR) & $-0.01 \pm 0.11$ & $-0.04 \pm 0.09$ & $-0.05 \pm 0.07$ & $-0.05 \pm 0.07$ & $-0.05 \pm 0.07$ & $-0.05 \pm 0.07$ \\
BCVA (logMAR) & $-0.05 \pm 0.09$ & $-0.08 \pm 0.07$ & $-0.09 \pm 0.05$ & $-0.10 \pm 0.05$ & $-0.10 \pm 0.06$ & $-0.10 \pm 0.06$ \\
Subjective cylindrical power (D) & $0.54 \pm 0.61$ & $0.53 \pm 0.56$ & $0.55 \pm 0.46$ & $0.61 \pm 0.45$ & $0.58 \pm 0.49$ & $0.55 \pm 0.47$ \\
\hline
\end{tabular}

BCVA Best corrected visual acuity, IOL Intraocular lens, logMAR Logarithm of the minimum angle of resolution, UCVA Uncorrected visual acuity, VA Visual acuity

the residual subjective cylindrical power (the dioptric power determined during subjective refraction) was less than $0.50 \mathrm{D}$ in $59 \%$ (36/61 eyes) and less than $1.00 \mathrm{D}$ in $89 \%$ (54/61 eyes) for all models combined.
Figure 2 presents the double angle polar plots. There were no remarkable changes observed between the preoperative corneal astigmatism (Fig. 2a) and the 12 months postoperative corneal astigmatism (Fig. 2b). However, in 

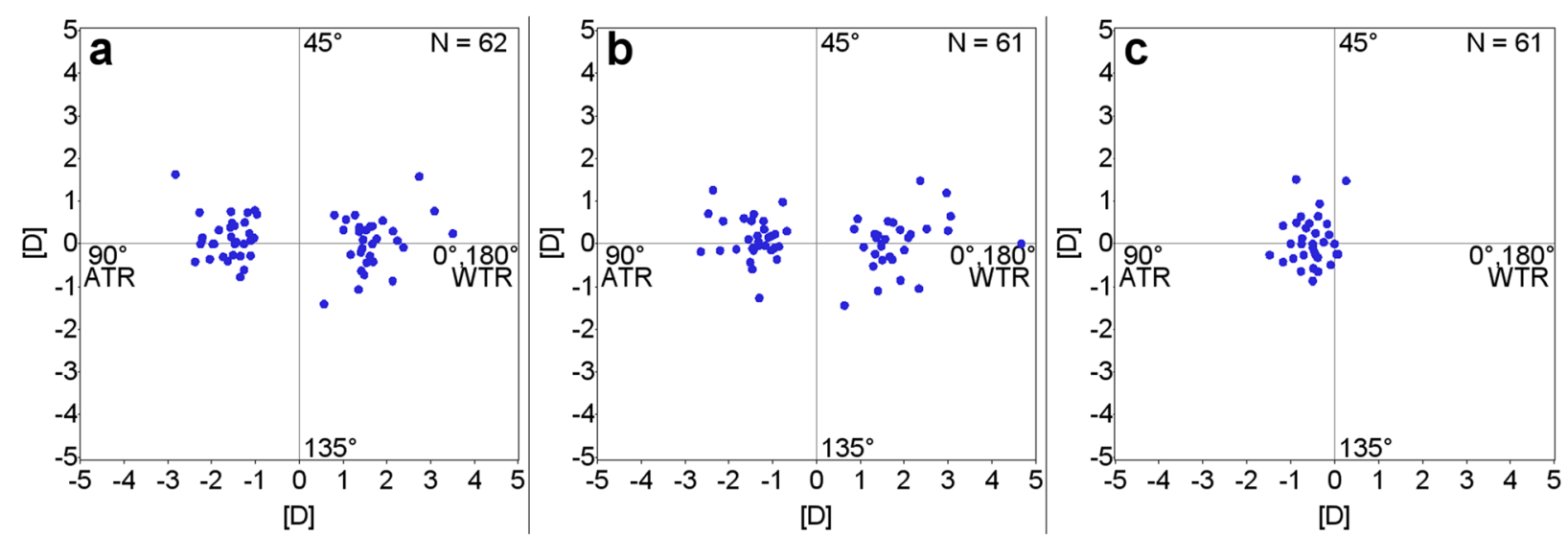

Fig. 2 Corneal astigmatism and postoperative subjective cylinder components (ATR=against-the-rule; WTR = with-the-rule). a Preoperative corneal astigmatism. b 12 months postoperative corneal astigmatism. c 12 months postoperative subjective cylinder components

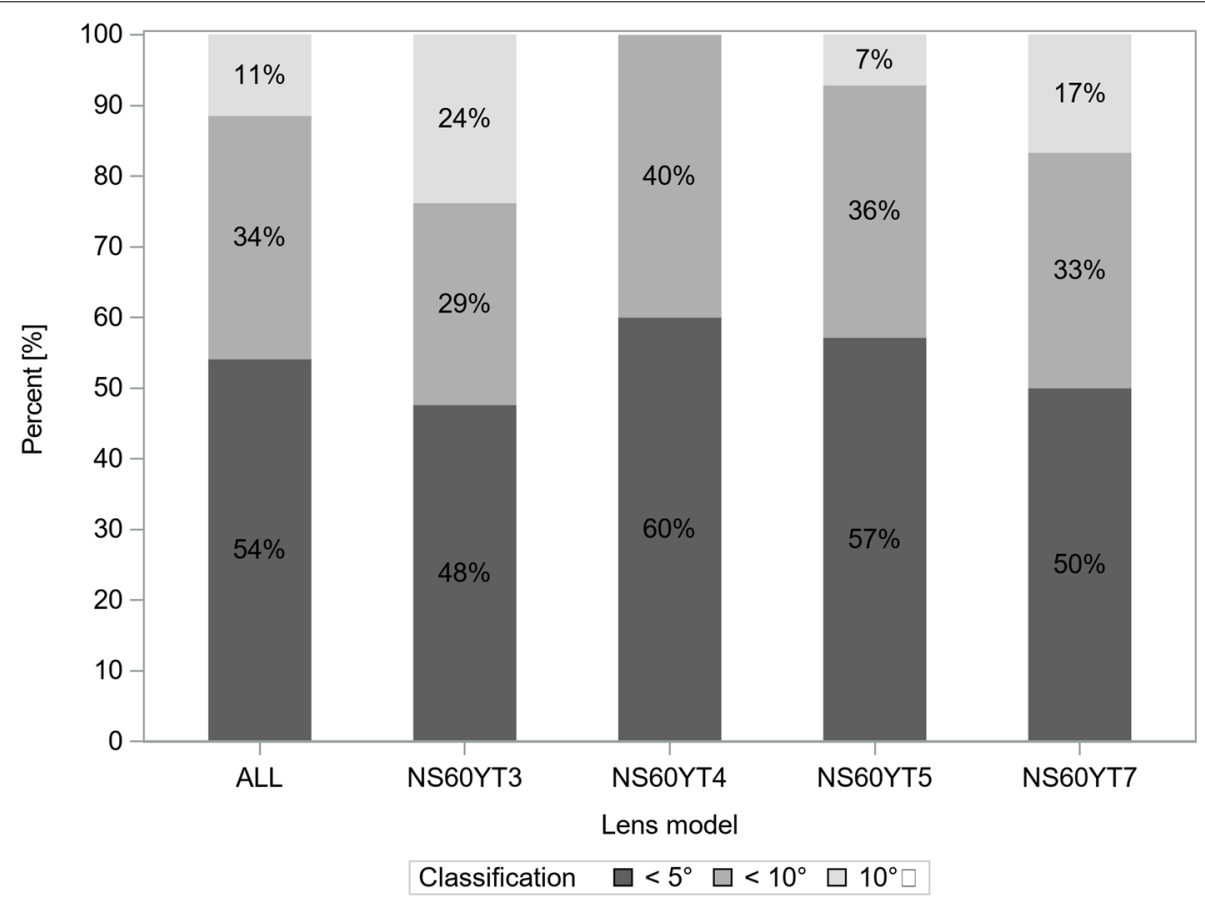

Fig. 3 Distribution of intraocular lens rotation at 12 months after surgery

eyes with subjective cylinder at 12 months postoperatively, the cylinder components tended towards againstthe-rule (ATR) astigmatism (Fig. 2c).

\section{Intraocular lens rotation (including additional analysis)}

Figure 3 presents the distribution of the rotation (absolute value) at 12 months compared to the axis of IOL insertion. A deviation less than $10^{\circ}$ between the IOL axis and the insertion axis was noted in $89 \%$ (54/61 eyes) of all models. No cases required repositioning surgery due to postoperative IOL rotation.

Additional analysis indicated that the magnitude of rotation the day after surgery was $5.5^{\circ}$, and the mean rotation between each examination after day 1 was $2.5^{\circ}$ or lower (Table 5). A rotation of $5.0^{\circ}$ or more occurred in $52 \%$ by day 1 , however, a rotation of $5.0^{\circ}$ or more after day 1 was 7 to $13 \%$ for each period (Table 5). At 12 months postoperatively, the IOL rotated clockwise in 61\% (37/61) 
Table 5 Rotational stability of the NS60YT intraocular lens

\begin{tabular}{|c|c|c|c|c|c|}
\hline \multirow[t]{2}{*}{ Postoperative } & \multirow{2}{*}{$\begin{array}{l}\text { Number of } \\
\text { eyes, } n\end{array}$} & \multirow{2}{*}{$\begin{array}{l}\text { Rotation amount (absolute } \\
\text { value) } \pm S D\left({ }^{\circ}\right)\end{array}$} & \multicolumn{3}{|c|}{ Lens rotation amount, $\mathrm{n}(\%)$} \\
\hline & & & Less than $5.0^{\circ}$ & $\begin{array}{l}5.0^{\circ} \text { or more and less } \\
\text { than } 10.0^{\circ}\end{array}$ & $10.0^{\circ}$ or more \\
\hline 1 day & 61 & $5.5 \pm 3.8$ & $29(48)$ & $22(36)$ & $10(16)$ \\
\hline 1 day to 1 week & 61 & $2.5 \pm 2.7$ & $55(90)$ & $4(7)$ & $2(3)$ \\
\hline 1 week to 1 month & 61 & $2.2 \pm 1.7$ & $55(90)$ & $6(10)$ & $0(0)$ \\
\hline 1 month to 3 months & 61 & $2.0 \pm 1.8$ & $56(92)$ & $5(8)$ & $0(0)$ \\
\hline 3 months to 6 months & 61 & $2.1 \pm 2.0$ & $53(87)$ & $8(13)$ & $0(0)$ \\
\hline 6 months to 12 months & 61 & $1.9 \pm 1.5$ & $57(93)$ & $4(7)$ & $0(0)$ \\
\hline 1 day to 12 months & 61 & $3.1 \pm 2.9$ & $47(77)$ & $11(18)$ & $3(5)$ \\
\hline
\end{tabular}

SD Standard deviation

of eyes, counterclockwise in $31 \%(19 / 61)$ of eyes, and the IOL did not rotate in $8 \%(5 / 61)$ of eyes. The direction of rotation and the preoperative corneal cylinder axis were not statistically associated (Fisher's exact test, $P=0.781$ ).

\section{Patient satisfaction}

A questionnaire at 6 months queried patient satisfaction. For all models, the results were "very satisfied" $52 \%$ (32/62 eyes), "satisfied" 40\% (25/62 eyes), "neither satisfied nor dissatisfied" 3\% (2/62 eyes), "dissatisfied" 5\% (3/62 eyes), and "very dissatisfied" $0 \%$ (0/62 eyes). Thus, "very satisfied" and "satisfied" accounted for $92 \%$ of eyes.

\section{Safety}

Postoperative adverse events where a causal relationship could not be ruled out included 4 eyes (6\%) with mild posterior capsule opacification. Anticipated adverse events (defined separately at the beginning of the study) developed in 6 eyes of 5 patients. These included 2 eyes (3\%) with secondary cataract (requiring posterior capsulotomy) and 4 eyes (6\%) with increased IOP. One patient died during the course of the study due to multiple organ failure which was a non-ocular adverse event and had no causal relationship to cataract surgery or IOL implantation.

\section{Discussion}

This prospective evaluation of a new toric IOL (NS60YT) indicated the majority of eyes had excellent vision after cataract surgery. The primary endpoint of the study was VA with spherical addition for this Japanese population. This index was used as the primary endpoint taking into consideration the tendency of lens selection in Japan. Japanese cataract patients tend to prefer some nearsightedness instead of emmetropia postoperatively. Using an VA with spherical addition as the primary endpoint enabled comparison with the published literature on toric IOLs targeting emmetropia despite targeting postoperative myopia (in the current study).

At 6 months postoperatively, 90\% (56/62 eyes) of all eyes achieved VA with spherical addition of $0.1 \log$ MAR or better. The lower limit (80\%) of the $95 \%$ CI exceeded the expected response rate of $70 \%$, which was the basis for determining the number of cases. This outcome indicates, that patients achieved equivalent or better postoperative visual acuity with the NS60YT in comparison with commercially available toric IOLs as the historical controls.

In contrast to the VA with spherical addition, spherecorrected VA is the visual acuity obtained by further correcting the postoperative spherical refractive error only. In addition, the BCVA is the best visual acuity obtained by further correcting the residual postoperative cylindrical power from the sphere-corrected VA. This means that the difference between the VA with spherical addition and the sphere-corrected VA is the spherical refractive error with respect to the target refractive power. Additionally, the difference between the sphere-corrected VA and the BCVA is the cylindrical refractive error. Twelve months after surgery, the outcomes of the current study indicate a sphere-corrected VA of less than $0.1 \log$ MAR in only one eye (2\%), and $0.1 \log$ MAR or better in the other 60 eyes (98\%). This outcome indicates excellent cylinder correction with the NS60YT.

Vector analysis indicated that the postoperative subjective cylinder had a distribution toward ATR astigmatism. This trend is similar to the outcomes of wavefront analysis reported by Ninomiya et al. [11]. The primary cause of ATR astigmatism after surgery could be due to the effect of posterior corneal astigmatism. As this study was designed in 2014, the protocol did not incorporate the effect of posterior corneal curvature. The current study used only the anterior corneal surface to evaluate corneal astigmatism, and the Nidek Toric Calculator For Clinical 
Trials did not consider the posterior corneal astigmatism for lens selection. Koch et al. [12] have reported that posterior corneal astigmatism causes overcorrection of with-the-rule (WTR) astigmatism and decreases the correction of ATR astigmatism when the lens selection is based on the anterior corneal astigmatism only. Hence, our outcomes are consistent with Koch et al's observations [13]. Savini et al. have published nomograms for selecting the IOL power when only the anterior corneal astigmatism is used. For preoperative WTR astigmatism, residual astigmatism is calculated based on the result from subtracting $0.59 \mathrm{D}$ to $0.70 \mathrm{D}$ from the predicted postoperative corneal astigmatism [14]. For preoperative ATR astigmatism, residual astigmatism is calculated based on the result of adding $0.32 \mathrm{D}$ to $0.70 \mathrm{D}$ to the predicted postoperative corneal astigmatism [14]. The current version of the Nidek Toric Calculator includes the Baylor nomogram to compensate for the posterior surface power when only anterior corneal surface data are used $[12,13]$.

Rotational stability of a toric IOL is crucial for achieving accurate cylinder correction. Every $1^{\circ}$ rotation of a toric IOL from the intended axis can decrease cylinder correction efficacy by $3.3 \%$. For example, a postoperative toric IOL rotation over $30^{\circ}$ results in additional astigmatism [15]. The outcomes of the current study indicate the NS60YT has good rotational stability. For example, the mean IOL rotation at 6 months was $5.0 \pm 4.4^{\circ}$ for all models combined which is well within the range reported for other IOLs. Previous studies have reported rotation of single-piece toric IOLs between the intended axis and the observed axis from $2^{\circ}$ to $9^{\circ}$ at 6 months postoperatively
[9, 16-20]. Additionally, in the current study, the magnitude of rotation ranged from $1.9^{\circ}$ to $2.5^{\circ}$ between each postoperative examination from 1 day to 12 months and the mean rotation was $3.1 \pm 2.9^{\circ}$. The tendency to rotate early in the postoperative period and then stabilize was similar to the previous literature on existing single-piece toric IOLs [21-23].

The anchor wing-haptic design contributes to the stability of the NS60YT toric IOL. The $90^{\circ}$ orientation of the anchor wing-haptic design makes it difficult to generate a force in the rotational direction from compression due to the pressure from capsular contraction. Additionally, the width between the haptic shoulders is based on an average capsular diameter. The design geometry allows a secure fit within the capsular bag using the shoulders to stabilize the IOL without relying on the overall haptics ('arms') of the IOL.

Table 6 presents data on seven cases with a rotation of $10^{\circ}$ or greater at 12 months postoperatively relative to the IOL insertion axis. Five cases (except Cases 3 and 4 ) rotated $10^{\circ}$ or more at 1 day. In Case 4 , a rotation of $10^{\circ}$ or more was observed initially at 1 month. This case had an incomplete closed capsulorhexis with 2 tears. Perhaps postoperative healing and suboptimal capsular contraction due to the tears may have played a role in the rotation. Case 3 presented with a rotation of $10^{\circ}$ or more initially at 12 months. The subsequent rotations were as follows: $-4^{\circ}$ at 1 week; $-2^{\circ}$ at 1 month; $-9^{\circ}$ at 3 months; $-9^{\circ}$ at 6 months; and $-13^{\circ}$ at 12 months. We are at a loss to explain the IOL rotation between visits. However we can rule out abnormal head positioning as experienced technicians, familiar with the equipment ensured the patient's head was in correct

Table 6 Cases with rotation of $10^{\circ}$ or greater at 12 months postoperatively

\begin{tabular}{|c|c|c|c|c|c|c|c|}
\hline & Case 1 & Case 2 & Case 3 & Case 4 & Case 5 & Case 6 & Case 7 \\
\hline Amount of rotation $\left({ }^{\circ}\right)^{a}$ & 15 & -16 & -13 & 10 & -18 & 18 & -12 \\
\hline Expected $\mathrm{IOL}$ axis angle $\left(^{\circ}\right)$ & 4 & 10 & 95 & 177 & 87 & 94 & 161 \\
\hline $\mathrm{IOL}$ axis angle $\left(^{\circ}\right)$ & 19 & 174 & 82 & 7 & 69 & 112 & 149 \\
\hline When the rotation exceeded $10^{\circ}$ & 1 day & 1 day & 12 months & 1 month & 1 day & 1 day & 1 day \\
\hline Model & NS60YT7 & NS60YT3 & NS60YT5 & NS60YT3 & NS60YT3 & NS60YT3 & NS60YT3 \\
\hline Spherical power (D) & 17.0 & 19.0 & 21.5 & 20.0 & 21.5 & 18.0 & 20.0 \\
\hline $\mathrm{AL}(\mathrm{mm})$ & 25.50 & 25.00 & 23.61 & 24.85 & 23.13 & 25.17 & 25.28 \\
\hline Age (y) & 72 & 63 & 45 & 72 & 58 & 59 & 70 \\
\hline Anterior capsulotomy & $\mathrm{CCC}$ & CCC & $\mathrm{CCC}$ & CCC with 2-tear & $\mathrm{CCC}$ & $\mathrm{CCC}$ & $\mathrm{CCC}$ \\
\hline VA with spherical addition (logMAR) & -0.08 & 0.22 & -0.18 & 0.15 & -0.08 & -0.08 & 0.05 \\
\hline Sphere-corrected VA (logMAR) & -0.08 & 0.22 & -0.18 & 0.05 & -0.08 & -0.18 & 0.00 \\
\hline BCVA (logMAR) & -0.18 & 0.05 & -0.18 & 0.00 & -0.08 & -0.18 & -0.08 \\
\hline (Cylinder correction amount) & $(-1.75 \mathrm{D})$ & $(-1.00 \mathrm{D})$ & $(-0.50 \mathrm{D})$ & $(-0.25 \mathrm{D})$ & $(-1.50 \mathrm{D})$ & $(-0.25 \mathrm{D})$ & $(-0.75 \mathrm{D})$ \\
\hline $\begin{array}{l}\text { Questionnaire results (at examination } \\
\text { of } 6 \text { months) }\end{array}$ & Very satisfied & Satisfied & Satisfied & Very satisfied & Very satisfied & Satisfied & Satisfied \\
\hline
\end{tabular}

AL Axial length, BCVA Best corrected visual acuity, CCC Continuous curvilinear capsulorhexis, IOL Intraocular lens, UCVA Uncorrected visual acuity, VA Visual acuity

${ }^{\text {a }}$ Rotation amount: plus $=$ counterclockwise, minus $=$ clockwise 
position prior to acquiring images. Although abnormal head position may have been missed at one visit, it would be highly unlikely in consecutive visits with the same patient. Additionally, the observation that the majority of patients were not symptomatic concurs with the low magnitude of rotation reported in the current study and indicates that relatively good image acquisition techniques and accurate measurements were used in the current study.

The cause of rotation in this case is unknown, however, the patient was asymptomatic and there were no postoperative sequelae. In cases with $10^{\circ}$ or greater postoperative IOL rotation, we recommended a re-rotation if the patient was symptomatic. In these cases, the VA with spherical addition was $0.1 \operatorname{logMAR}$ or better with Cases 2 and 4 excluded, and the sphere corrected VA was $0.05 \log$ MAR or better with Case 2 excluded. Patient satisfaction with their vision remained high in all cases with a rotation of $10^{\circ}$ or more.

This study evaluated the difference of the IOL axis at each postoperative examination relative to the insertion axis. Therefore, the evaluation included assessment of the IOL axis deviation intraoperatively and the rotation from the early postoperative phase onwards. To verify the rotation from the insertion axis more accurately, deviation between the expected insertion axis and the actual insertion axis needs to be evaluated.

\section{Conclusions}

In summary, the outcomes of this study indicate that a new toric IOL with anchor-wing haptics is safe and effective for implantation during cataract surgery. Axis rotation was very low in the majority of cases and clinically insignificant and repositioning of the IOL was not warranted in any patient. Implantation of this toric IOL provides satisfactory postoperative visual acuity and good patient satisfaction.

\begin{abstract}
Abbreviations
ATR: Against-the-rule; AL: Axial length; BCVA: Best corrected visual acuity; CCC: Continuous curvilinear capsulorhexis; Cl: Confidence interval; D: Diopter; GCP: Good clinical practice; IOL: Intraocular lens; IOP: Intraocular pressure; LogMAR: Logarithm of the minimum angle of resolution;; OBL: Oblique; SD: Standard deviation; UCVA: Uncorrected visual acuity; VA: Visual acuity; WTR: With-the-rule.
\end{abstract}

\section{Acknowledgements}

Not applicable.

\section{Authors' contributions}

$\mathrm{KN}$ and $\mathrm{HT}$ contributed to the study conception and design. Material preparation, data collection and analysis were performed by IS, TO, KI, TO, TN, and HT. The first draft of the manuscript was written by IS and all authors commented on previous versions of the manuscript. All authors read and approved the final manuscript, and agreed both to be personally accountable for the author's own contributions and to ensure that questions related to the accuracy or integrity of any part of the work, even ones in which the author was not personally involved, are appropriately investigated, resolved, and the resolution documented in the literature.

\section{Funding}

The study sponsor, NIDEK CO., LTD. (Aichi, Japan) provided funding to each investigator's academic institution or private practice to conduct the clinical trial and provided personal fees to a medical expert. The study devices were provided by the sponsor. The funding body played no role in the design of the study and collection, analysis, and interpretation of data and in writing the manuscript.

\section{Availability of data and materials}

The datasets used and analyzed during the current study are available from the corresponding author on reasonable request.

\section{Declarations}

\section{Ethics approval and consent to participate}

This study adhered to the principles of the Declaration of Helsinki. This study was approved by the Jikei University Hospital Institutional Review Board for Medical Devices, the Sugita Eye Hospital Institutional Review Board, and the Joint Institutional Review Board of the hospitals. Written informed consent was obtained from all individual participants included in the study.

\section{Consent for publication}

Not applicable.

\section{Competing interests}

Dr. Sugita, Ogawa, Ichikawa, Okita, Nakano, and Tsuneoka report grants and Dr. Negishi report personal fees from NIDEK CO., LTD., during the conduct of the study;. Dr. Sugita reports grants and personal fees from Alcon Japan Ltd., personal fees and non-financial support from Santen Pharmaceutical Co., Ltd., non-financial support from HOYA Corporation, personal fees from Kowa Co., Ltd., grants and personal fees from Senjyu Pharmaceutical Co., Ltd., personal fees from Carl Zeiss Meditec AG, personal fees from Bayer AG, personal fees from Pfizer Inc., personal fees from Nikon Corporation, outside the submitted work; Dr. Ichikawa reports grants and personal fees from Alcon, grants and personal fees from ZEISS, grants and personal fees from STAAR, personal fees from HOYA, personal fees from SANTEN, personal fees from KY CenterVue, personal fees from Igaku shoin, personal fees from Kowa, personal fees from JFC, personal fees from Novartis, outside the submitted work; Dr. Negishi reports grants from Fuji Xerox Co, grants from Hitachi Automotive Systems, Ltd., grants from Universal View Co., Ltd., grants and personal fees from Alcon Japan Ltd., grants and personal fees from Santen Pharmaceutical, grants and personal fees from HOYA Corporation, grants and personal fees from AMO Japan K.K., grants from Kowa Company, grants from Kowa Pharmaceutical Company Ltd., grants from Tomey Corporation, personal fees from Senju Pharmaceutical, personal fees from Otsuka Pharmaceutical, personal fees from NIDEK Co., Ltd., personal fees from Carl Zeiss Meditec AG, outside the submitted work; Dr. Negishi has a patent (PCT/JP2015/65997, PCT/JP2016/085903) for potential products for myopia suppression pending to Tsubota Laboratory Inc.

\section{Author details}

${ }^{1}$ Sugita Eye Hospital, 5-1-30, Sakae, Naka-ku, Nagoya-shi, Aichi 460-0008, Japan. ${ }^{2}$ Department of Ophthalmology, the Jikei University School of Medicine, 3-25-8, Nishi-Shimbashi, Minato-ku, Tokyo 105-8461, Japan. ${ }^{3}$ Miyamaedaira Ogawa Eye Clinic, 19-14, Nanpeidai, Miyamae-ku, Kawasaki-shi, Kanagawa 216-0024, Japan. ${ }^{4}$ Chukyo Eye Clinic, 12-22, Sanbonmatsu-cho, Atsuta-ku, Nagoya-shi, Aichi 456-0032, Japan. ${ }^{5}$ Department of Ophthalmology, Keio University School of Medicine, 35 Shinanomachi, Shinjuku-ku, Tokyo 160-8582, Japan.

Received: 11 August 2020 Accepted: 30 December 2021 Published online: 15 January 2022

\section{References}

1. Ferrer-Blasco T, Montés-Micó R, Peixoto-de-Matos SC, González-Méijome $J M$, Cerviño A. Prevalence of corneal astigmatism before cataract surgery. J Cataract Refract Surg. 2009;35:70-5.

2. Hoffer KJ. Biometry of 7,500 cataractous eyes. Am J Ophthalmol. 1980;90:360-8. 
3. Ninn-Pedersen K, Stenevi U, Ehinger B. Cataract patients in a defined Swedish population 1986-1990. II Preoperative observations. Acta Ophthalmol. 1994;72:10-5.

4. Hoffmann PC, Hütz WW. Analysis of biometry and prevalence data for corneal astigmatism in 23,239 eyes. J Cataract Refract Surg. 2010;36:1479-85.

5. Behndig A, Montan P, Stenevi U, Kugelberg M, Zetterström C, Lundström M. Aiming for emmetropia after cataract surgery: Swedish National Cataract Register study. J Cataract Refract Surg. 2012;38:1181-6.

6. Wilkins MR, Allan B, Rubin G. Spectacle use after routine cataract surgery. Br J Ophthalmol. 2009;93:1307-12.

7. Kessel L, Andresen J, Tendal B, Erngaard D, Flesner P, Hjortdal J. Toric intraocular lenses in the correction of astigmatism during cataract surgery: a systematic review and Meta-analysis. Ophthalmology. 2016;123:275-86.

8. Alcon Research Ltd. Summary of safety and effectiveness data ACRYSOF ${ }^{\circledR}$ Single-Piece Posterior Chamber Intraocular Lenses With Toric Optic. 2005. https://www.accessdata.fda.gov/cdrh_docs/pdf/P930014S01 5b.pdf. Accessed October 27, 2019.

9. Ahmed II, Rocha G, Slomovic AR, Climenhaga H, Gohill J, Grégoire A, et al. Canadian Toric study group. Visual function and patient experience after bilateral implantation of toric intraocular lenses. J Cataract Refract Surg. 2010;36:609-16.

10. Bauer NJ, de Vries NE, Webers CA, Hendrikse F, Nuijts RM. Astigmatism management in cataract surgery with the AcrySof toric intraocular lens. J Cataract Refract Surg. 2008;34:1483-8.

11. Ninomiya $Y$, Kojima Y, Maeda N. Assessment of astigmatism correction in cataract surgery with toric intraocular lens using vector analysis. Rinsho Ganka. 2012;66:1147-52.

12. Koch DD, Ali SF, Weikert MP, Shirayama M, Jenkins R, Wang L. Contribution of posterior corneal astigmatism to total corneal astigmatism. J Cataract Refract Surg. 2012;38:2080-7.

13. Koch DD, Jenkins RB, Weikert MP, Yeu E, Wang L. Correcting astigmatism with toric intraocular lenses: effect of posterior corneal astigmatism. J Cataract Refract Surg. 2013;39:1803-9.

14. Savini G, Næser K. An analysis of the factors influencing the residual refractive astigmatism after cataract surgery with toric intraocular lenses. Invest Ophthalmol Vis Sci. 2015;56:827-35.

15. Shimizu K, Misawa A, Suzuki Y. Toric intraocular lenses: correcting astigmatism while controlling axis shift. J Cataract Refract Surg. 1994;20:523-6.

16. Koshy J, Nishi Y, Hirnschall N, et al. Rotational stability of a single-piece toric acrylic intraocular lens. J Cataract Refract Surg. 2010;36:1665-70. https://doi.org/10.1016/j.jcrs.2010.05.018.

17. Alió JL, Piñero DP, Tomás J, Alesón A. Vector analysis of astigmatic changes after cataract surgery with toric intraocular lens implantation. J Cataract Refract Surg. 2011;37:1038-49. https://doi.org/10.1016/j.jcrs.2010.12.053.

18. Visser N, Ruíz-Mesa R, Pastor F, Bauer NJ, Nuijts RM, Montés-Micó R. Cataract surgery with toric intraocular lens implantation in patients with high corneal astigmatism. J Cataract Refract Surg. 2011;37:1403-10. https:// doi.org/10.1016/j.jcrs.2011.03.034.

19. Visser N, Beckers HJM, Bauer NJC, et al. Toric vs Aspherical control intraocular lenses in patients with cataract and corneal astigmatism: a randomized clinical trial. JAMA Ophthalmol. 2014;132:1462-8. https://doi. org/10.1001/jamaophthalmol.2014.3602.

20. Hirnschall N, Gangwani V, Crnej A, Koshy J, Maurino V, Findl O. Correction of moderate corneal astigmatism during cataract surgery: toric intraocular lens versus peripheral corneal relaxing incisions. J Cataract Refract Surg. 2014;40:354-61. https://doi.org/10.1016/j.jcrs.2013.08.049.

21. Weinand F, Jung A, Stein A, Pfützner A, Becker R, Pavlovic S. Rotational stability of a single-piece hydrophobic acrylic intraocular lens: new method for high-precision rotation control. J Cataract Refract Surg. 2007;33:800-3. https://doi.org/10.1016/j.jcrs.2007.01.030.

22. Hirnschall N, Maedel S, Weber M, Findl O. Rotational stability of a singlepiece toric acrylic intraocular lens: a pilot study. Am J Ophthalmol. 2014;157(2):405-411.e1. https://doi.org/10.1016/j.ajo.2013.09.032

23. Waltz KL, Featherstone K, Tsai L, Trentacost D. Clinical outcomes of TECNIS toric intraocular lens implantation after cataract removal in patients with corneal astigmatism. Ophthalmology. 2015;122(1):39-47. https://doi.org/ 10.1016/j.ophtha.2014.06.027

\section{Publisher's Note}

Springer Nature remains neutral with regard to jurisdictional claims in published maps and institutional affiliations.
Ready to submit your research? Choose BMC and benefit from:

- fast, convenient online submission

- thorough peer review by experienced researchers in your field

- rapid publication on acceptance

- support for research data, including large and complex data types

- gold Open Access which fosters wider collaboration and increased citations

- maximum visibility for your research: over $100 \mathrm{M}$ website views per year

At BMC, research is always in progress.

Learn more biomedcentral.com/submissions 